\title{
A study on the Characteristics of Heat Transfer of Condensers with Various Insert Devices of Loop Type Two Phase Thermosyphons
}

\author{
Dong-Hyun Cho \\ The University of Daejin, 1007, Hogukro, Pocheonsi, Gyeinggodo, 11159, \\ Republic of Korea \\ chodh@daejin.ac.kr
}

\begin{abstract}
Two-phase thermosyphons are devices that can transfer large amounts of heat flux with the boiling and condensation of the working fluid resulting from small temperature differences. A two-phase thermosyphon consists of the evaporators, an insulation unit, and the condensers. The working fluid inside the evaporator is evaporated by the heating of the evaporator in the lower part of the two-phase thermosyphon and the evaporated steam rises to the in the upper part to transfer heat in response to the cooling fluid outside the tube. The resultant condensed working fluid flows downward along the inside surface of the tube due to gravity. The resultant condensed working fluid flows downward along the inside surface of the tube due to gravity. These processes form a cycle. In the present study, condensers with various insert devices of a loop type two-phase thermosyphon which is $480 \mathrm{~mm}$ wide, $68 \mathrm{~mm}$ long, and 1,000mm high was used. The heat transfer pipes in the loop type two-phase thermosyphon were $15 \mathrm{~mm}$ in diameter and 1,000mm in length and 98 heat transfer pipes were installed in loop type two-phase thermosyphon. The inside of the condensers with various insert devices was composed of heat transfer pipes installed to increase the heat transfer surface area of the heating media in the heat transfer pipes condensers with various insert devices. Using refrigerant R134a as a working fluid for the loop type two-phase thermosyphon to conduct heat transfer performance experiments for changes in the temperature of the cooling air outside the condenser and changes in the mass flow rate. According to the results of the present experiments, as the spaces between internal discontinuous pins decreased, pressure drops increased. Changes in the temperatures at the outlet of the condenser were shown to be a little smaller. Therefore, it can be seen that as the spaces between internal discontinuous pins decreased, the heat transfer performance increased. As the temperature of the air flowing in the condenser with various insert devices increased, the condensation heat transfer rate of the thermosyphon increased. As the condenser with various insert devices refrigerant inflow temperature increased, the condensation heat transfer rate of the condensers with various insert devices of the thermosyphon heat exchanger increased.
\end{abstract}

Keywords: Loop type two-phase thermosyphon, Condenser, Insert devices, Heat transfer, Performance

\section{Introduction}

Large amounts of heat are generated by high speed rotation of the rotating shafts of high voltage motors, power generators, and large lathes. For normal operation of those systems, a process to release the large amounts of the generated heat using a cooling system is essential[1]. Currently, cooling systems using cooling water or oil as a cooling fluid are widely utilized in South Korea and other countries too[2]. However, since such existing cooling systems are composed of many additional elements such as heat 
exchangers for heat removal, cooling fluid circulating pumps, cooling fluid circulating pipe, chillers for cooling fluid heat removal, cooling fluid flow control valves, and cooling fluid flow control devices, not only their structures are complicated but also they are expensive, consume large amounts of electricity, induce corrosion, and cause damage to electrical components when leaks occur[3]. In addition, such existing cooling systems use driving devices such as pumps to circulate cooling fluids and this leads to shortcomings such as lower reliability and increased sizes and weights. When seawater or fresh water is used as a cooling fluid, leaks of the cooling fluid will bring about fatal damage and corrosion and contamination will shorten the life the cooling system and will lead to excessive maintenance costs[4]. However, cooling systems using loop type twophase flexible thermosiphon technology can improve cooling performance because these systems release heat using the latent heat resulting from the boiling and condensation of the working fluid so that high performance systems can be implemented and the prices, sizes, and power consumption of the systems can be reduced[5, 6]. As such, cooling systems with high speed rotating shafts using the loop type two-phase thermosiphon technology can be made at much lower prices compared to existing cooling systems because they do not require devices such as cooling fluid circulating pumps and chillers. Crain et al. showed that the slope of the condenser was very important because it was associated with dry-out in the circuit and that the thermal performance of the system would be poor if the amount of the working fluid filled in the system was too large[7]. Faghri et al. conducted an experimental and analytical study on the flow and heat transfer of two-phase closed thermosiphon loops[8]. The main purpose of the present study is to develop condenser with internal fins and external plate fins of a loop type two-phase flexible thermosyphon heat exchanger that can release the large amounts of heat generated by the high speed rotation of the high speed rotating shafts of high voltage motors, power generators, and large lathes, conduct experiments for the performance, and develop design programs for optimum designs. In addition, in the present study, the performance of condenser with internal fins and external plate fins of a loop type two-phase flexible thermosyphon heat exchanger made through experiments and the effects of various variables were observed, simulations were implemented to evaluate the performance, and the results were verified through comparison with experimental results.

\section{Experimental Apparatus and Method}

Figure 1 shows the experimental facility for the loop type two-phase thermosyphon for high speed rotating shaft heat release and Figure 2 shows the loop type two-phase thermosyphon for high speed rotating shaft heat release. The loop type two-phase thermosyphon is installed with an evaporator which is a heating section and a condenser which is a cooling section that are separated from each other. The evaporator and the condenser are assemblies of pipes composed of many pipes and they are constructed so that they are connected to each other through pipes gathered on the top and bottom. The evaporator and the condenser have conveying pipes in charge of working fluid flows connected to each other and the condenser is installed with a gas/liquid separator that gathers non-condensable gases and an exhaust gas valve. In loop type thermosyphon, because of the characteristics of thermosyphons, the condenser should be installed at a higher location than the evaporator without fail to obtain the pressure difference for circulation of the working fluid. As shown in Figure3, the evaporator of the $6.5 \mathrm{~kW}$ grade loop type thermosyphon heat exchanger made for the present study is $699 \mathrm{~mm}$ in the outside diameter, $630 \mathrm{~mm}$ in the inside diameter, and $150 \mathrm{~mm}$ in the height. In addition, 98 pieces of $12 \mathrm{~mm}$ diameter copper pipes were installed in the inside of the evaporator and 100 pieces of $12 \mathrm{~mm}$ diameter copper pipes were installed on the outside of the evaporator. Furthermore, L type $25 \mathrm{~mm}$ soft copper pipes were installed on the top and bottom of the evaporator. Figure 4 shows the condenser heat exchanger. The condenser is 
$480 \mathrm{~mm}$ wide, $1000 \mathrm{~mm}$ long and $68 \mathrm{~mm}$ high. The shape of the condenser heat exchanger plate and the

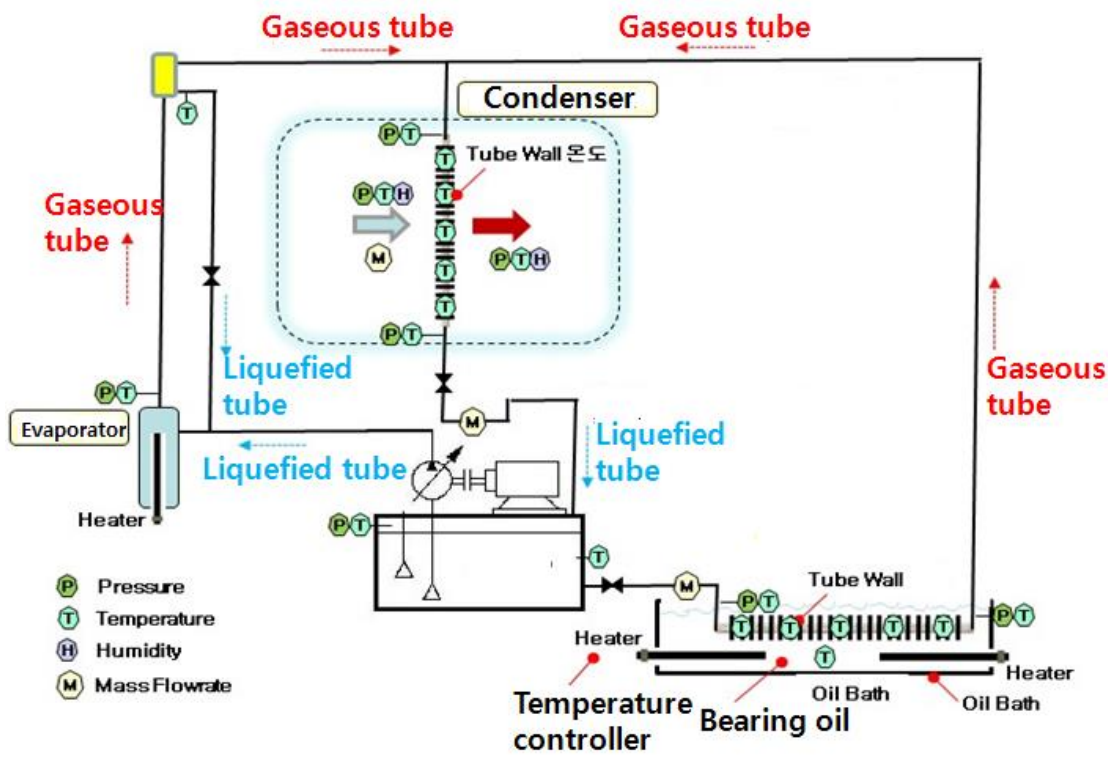

Figure 1. Schematic Diagram of the Experimental Facility

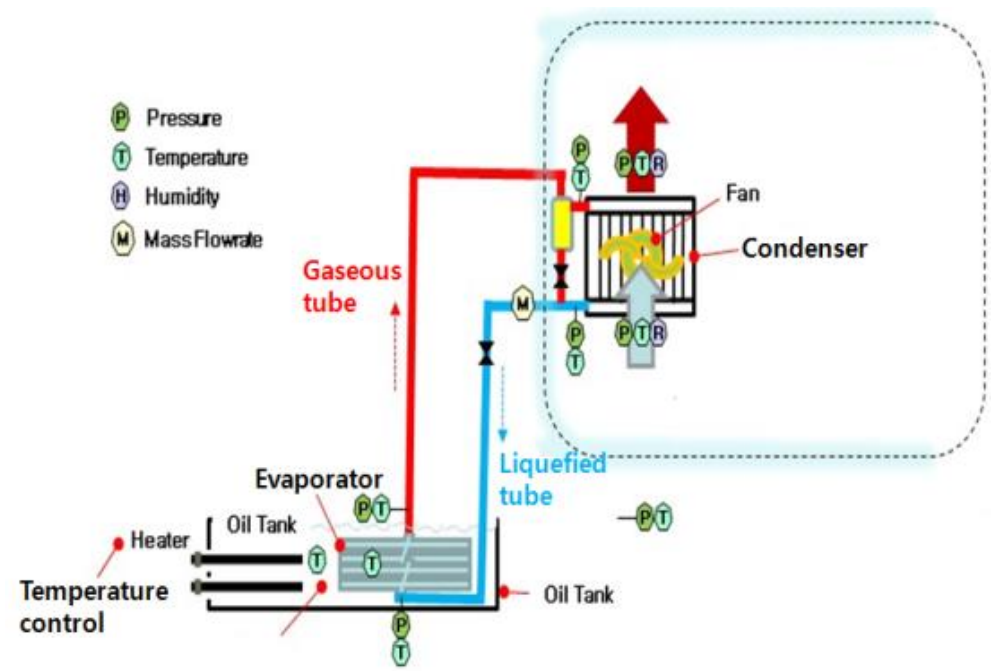

\section{Figure 2. Loop Type Two-Phase Thermosyphon Heat Exchangers for High Speed Rotating Shaft Heat Release}

Shape of the insert device inside the condenser are shown. Eighty $12 \mathrm{~mm}$ diameter, $1,000 \mathrm{~mm}$ long copper pipes were installed on the condenser. In addition, exhaust valves were attached to the condenser so that the working fluid can be filled and noncondensable gases can be exhausted. As shown in Figure 2, for performance experiments of the $6.5 \mathrm{~kW}$ grade loop type thermosyphon heat exchanger, the height difference between the evaporator and the condenser was set to $1.75 \mathrm{~m}$. The outside diameter of the conveying pipe that connects the evaporator with the condenser is $20 \mathrm{~mm}$. To prevent leaks from occurring in the conveying zone that connected the evaporator with the condenser, the conveying zone was checked using high pressure nitrogen and the conveying zone was insulated with $25 \mathrm{~mm}$ thick glass fibers to reduce heat losses to the outside of pipes occurring when the working fluid flows through the steam and fluid flow 
pipes. To measure individual experimental data in the performance experimental facility, Pressure Transducers were installed at the working fluid inlet/outlet of the evaporator so that the saturated vapor pressure of the working fluid can be measured and reviewed in comparison with the saturation temperature. To measure pressure drops in the vapor tube, Pressure Transducers were installed at the inlet/outlet of the condenser. One thermocouple each was installed at each of the inlet/outlet of the evaporator and the inlet/outlet of the condenser. To measure the oil temperature in the housing of the evaporator and the air temperature in the condenser, three each of thermocouples were installed at the inlet and out let respectively. The experimental data were measured and recorded using a Hybrid Recorder (64 channels). A refrigerant flowmeter was installed at the condenser outlet tube to measure the condensate refrigerant flow rate. In loop type thermosyphon heat exchanger performance experiments, initial temperatures are very important. Therefore, the non-condensable gases remaining in the tube were discharged so that a constant degree of vacuum is maintained in normal states. R-134a was used as a working fluid. The quantity of the injected working fluid was measured on a scale. A Slidacs was installed to maintain the oil temperature in the oil housing that supplies heat to the evaporator at $20 \sim 80^{\circ} \mathrm{C}$ when the experiment was conducted. The temperatures of the working fluid at the inlet and outlet of the evaporator and the condenser at individual layers were compared.



Figure 3. Schematic Diagram of the Evaporator

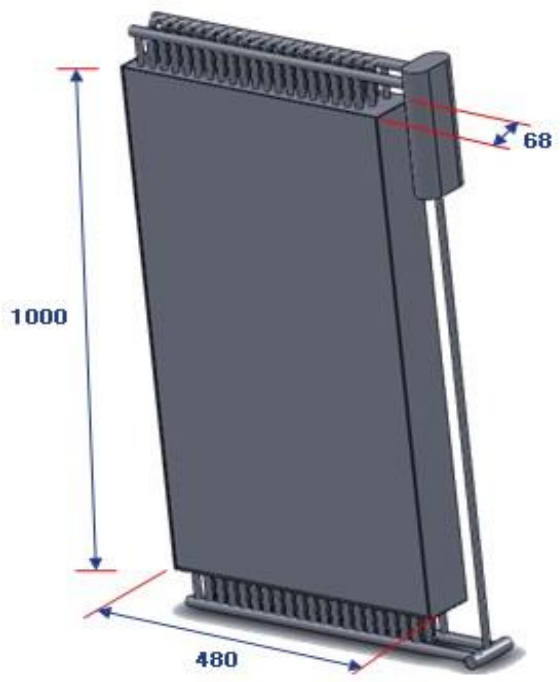

Figure 4. Condenser 


\section{Result and Discussion}

\subsection{Condenser Thermal Flow Analysis}

Figure 5 shows the mesh generation of the heat-transfer pipes of the condenser of the loop type two-phase thermosyphon and boundary conditions. Figure 6 and Figure 7 show basic modeling and grid generation of heat transfer. ANSYS FLUENT v13.0 was used as a condenser model. Only 1/4 of the circular tube of the condenser was constructed and symmetry conditions were given to the wall to implement heat and flow simulations.

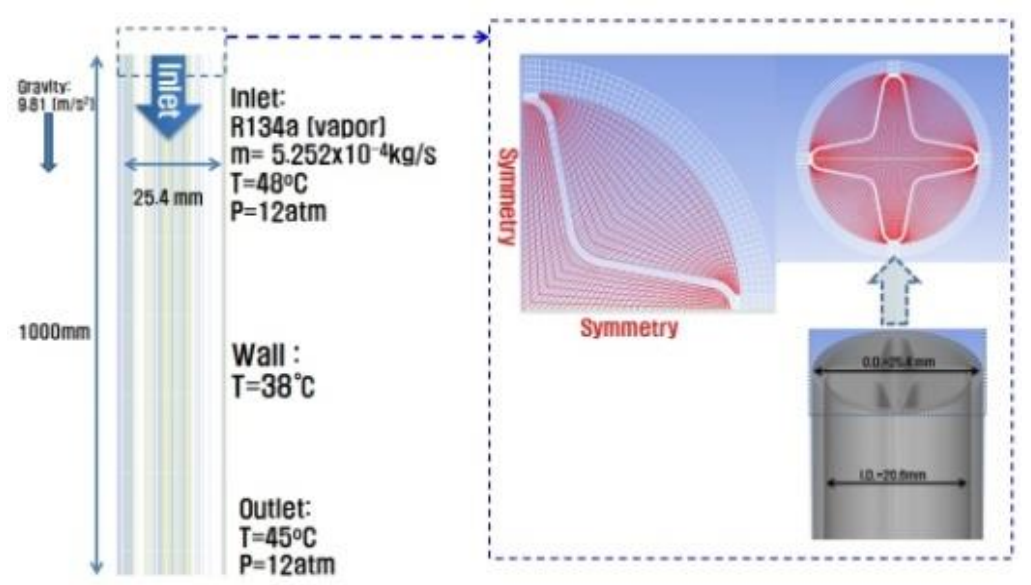

Figure 5. Condenser Shape and Mesh Generation

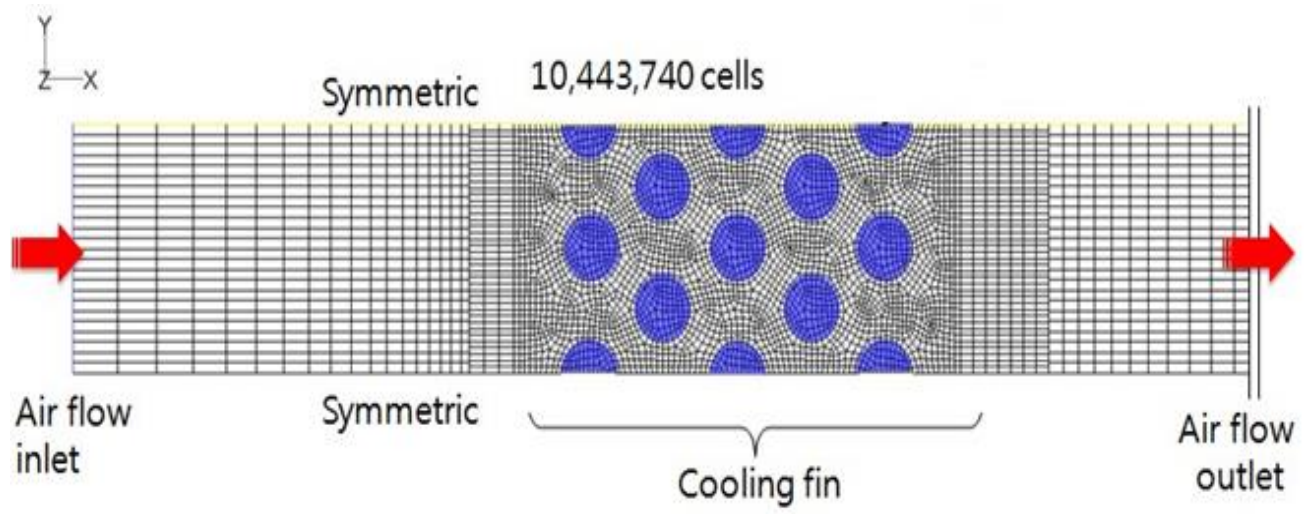

Figure 6. Basic Modeling and Grid Generation of Air Flow

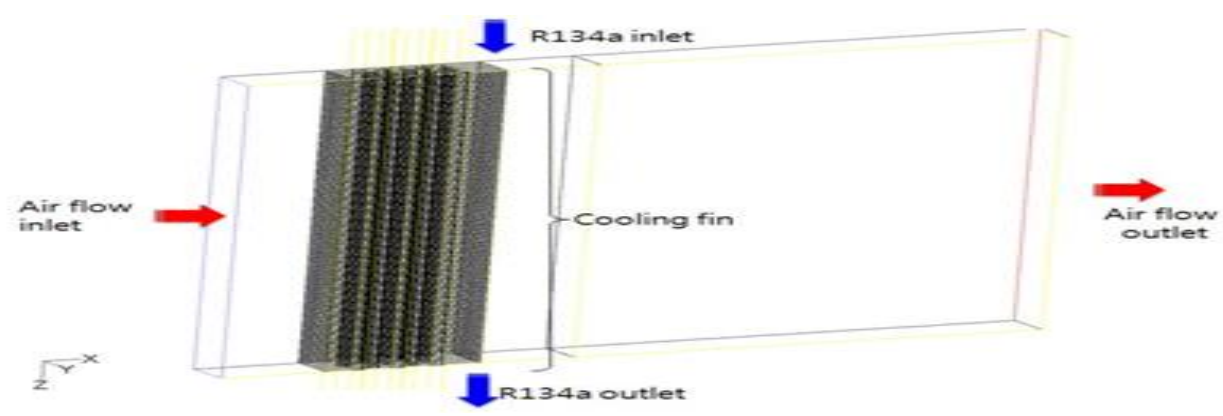

Figure 7. Basic Modeling and Grid Generation of Heat Transfer of Condenser 
Table 1 shows condenser simulation cases. The simulations were implemented with $0.1 \mathrm{~mm}$ thick internal pins at angles of $110^{\circ}, 124^{\circ}$, and $144^{\circ}$ under three length conditions; $50 \mathrm{~mm}, 75 \mathrm{~mm}$, and $100 \mathrm{~mm}$. The condenser is installed with 625 plate pins on its surface. The heat transfer area of one pin is $4.503 \mathrm{E}-3 \mathrm{~m}^{2}$ and that of 625 pins is $2.815 \mathrm{~m}^{2}$. Since the condenser tube area is $0.08 \mathrm{~m}^{2}$, the entire heat transfer area of the condenser including 625 plate pins is $2.895 \mathrm{~m}^{2}$. Figure 8 shows the results of simulations in cases $1 \sim 3$ shown in Table 1. As shown in Figure 8, cases 1 3 show the results of simulations with $0.1 \mathrm{~mm}$ thick internal pins fixed at an angle of $144^{\circ}$ with different spaces between internal discontinuous pins. It can be seen that differences in spaces between internal discontinuous pins have considerable effects on refrigerant flows. As the spaces between internal discontinuous pins decreased, pressure drops increased. Changes in the temperatures at the outlet of the condenser were shown to be a little smaller. Therefore, it can be seen that as the spaces between internal discontinuous pins decreased, the heat transfer performance increased

\section{Table 1. Simulation Cases of Condenser Section}

\begin{tabular}{|c|c|c|c|}
\hline CASE & $\delta_{(\mathrm{mm})}$ & $\theta_{(\text {degree })}$ & $\operatorname{Lf}(\mathrm{mm})$ \\
\hline 1 & 1.0 & 144 & 50 \\
\hline 2 & 1.0 & 144 & 75 \\
\hline 3 & 1.0 & 144 & 100 \\
\hline
\end{tabular}

It can be seen that differences in spaces between internal discontinuous pins have considerable effects on refrigerant flows and that as the spaces between internal discontinuous pins decreased, pressure drops increased and heat transfer performance improved. Figure 8 shows the results of simulations in cases $1 \sim 3$ that were implemented with $0.1 \mathrm{~mm}$ thick internal pins fixed at an angle of $144^{\circ}$ with different spaces between internal discontinuous pins. It can be seen that differences in spaces between internal discontinuous pins have considerable effects on refrigerant flows and that as pin lengths increased, heat transfer performance improved

\subsection{Results of Condenser Experiments}

Figure 9 and 10 show the results of condenser experiments. Figure 9 shows changes in pressure of condenser following changes in the temperature of the cooing are flowing in the condenser. The refrigerant used in the experiment is 134a. The experiment was conducted with the quantity of the refrigerant filled in the condenser in a range of $6 \sim 9 \mathrm{~kg}$. The air flowing in the condenser was in a range of $0.58 \sim 1.36 \mathrm{~kg} / \mathrm{s}$ when the experiment was conducted. As the condenser air temperature increased, the pressure of condenser also increased. Therefore, it can be seen that as the temperature of the air flowing in the condenser increases, the condensation heat transfer rate of the thermosyphon heat exchanger increases. Figure 10 shows changes in the oil temoerature following changes in the temperature of the cooing are flowing in the condenser. The refrigerant used in the experiment is $134 \mathrm{a}$. The experiment was conducted with the quantity of the refrigerant filled in the condenser in a range of $6 \sim 9 \mathrm{~kg}$. The air flowing in the condenser was in a range of $0.58 \sim 1.36 \mathrm{~kg} / \mathrm{s}$ when the experiment was conducted. As the condenser air temperature increased, the condenser refrigerant circulation rate also increased. Therefore, it can be seen that as the temperature of the air flowing in the condenser increases, the condensation heat transfer rate of the thermosyphon heat exchanger increases. 

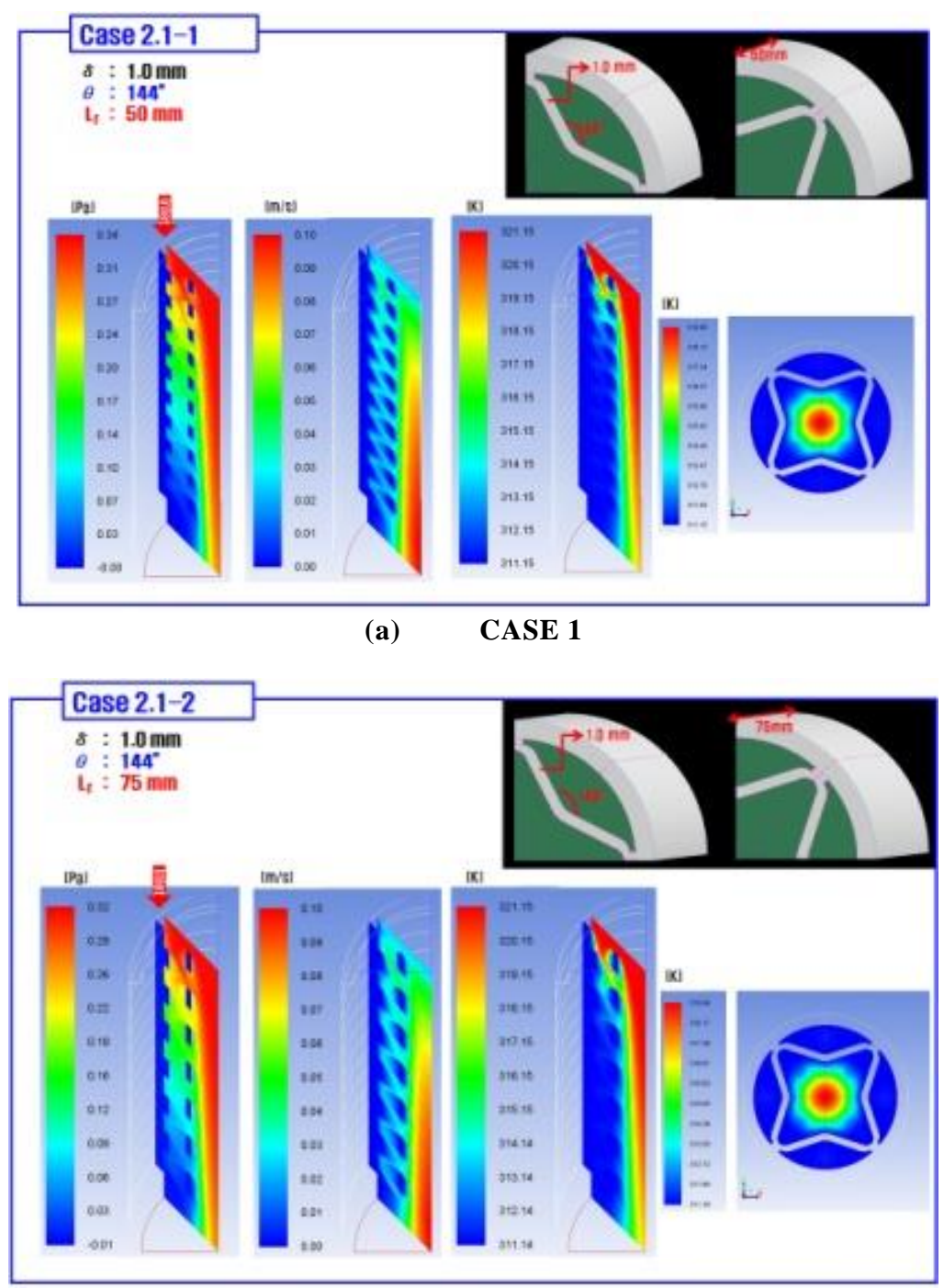

(b) CASE 2

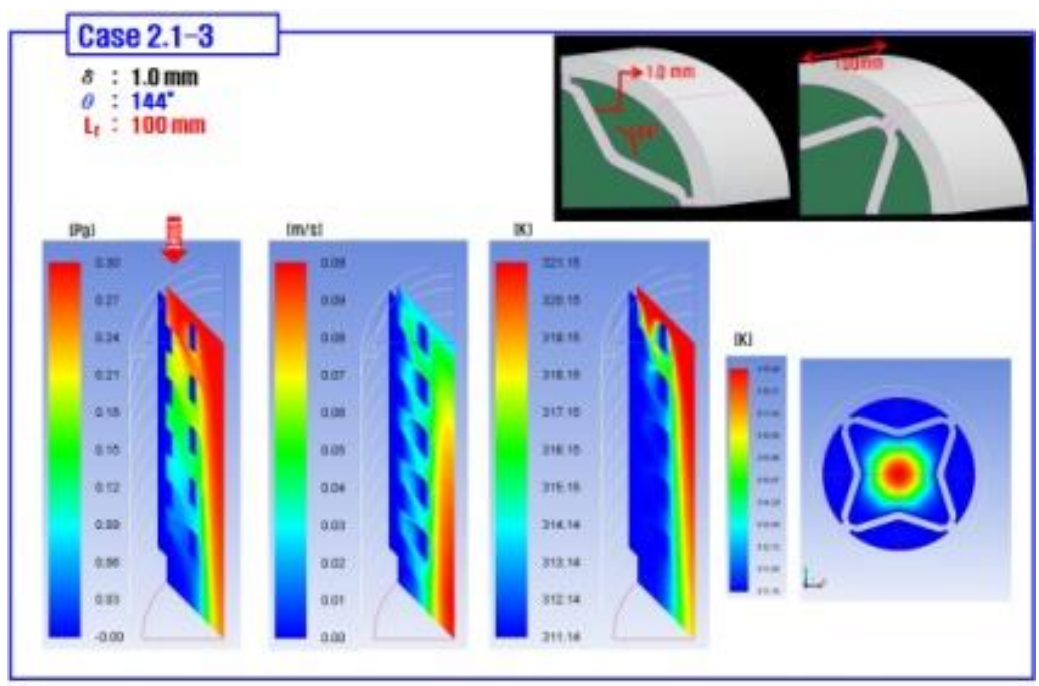

(c) CASE 3

Figure 8. Simulation Results of Case1 3 


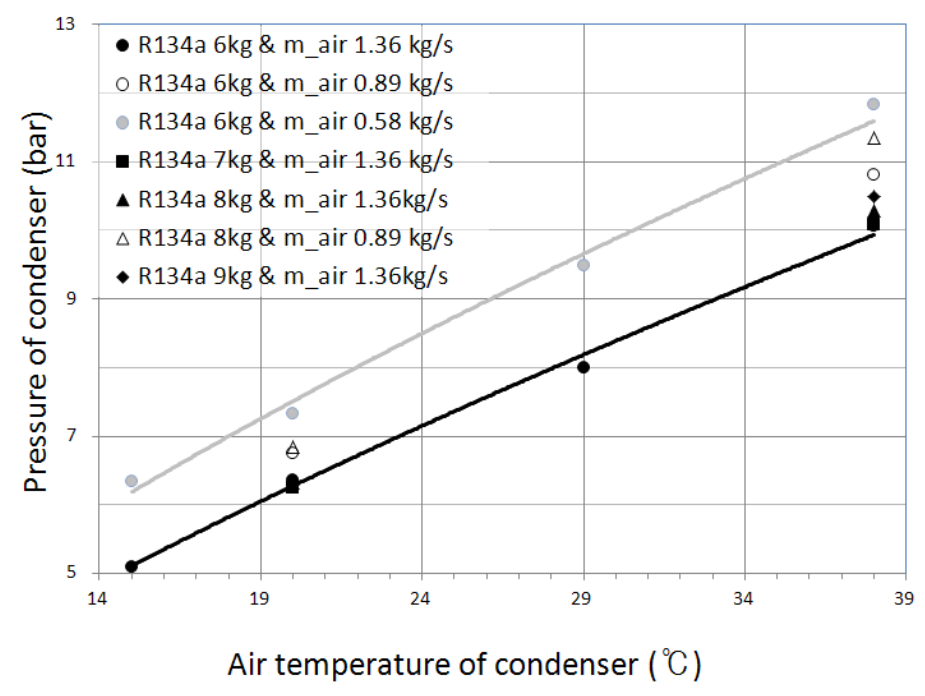

Figure 9. Comparison of Pressure of Condenser with Air Temperature of Condenser

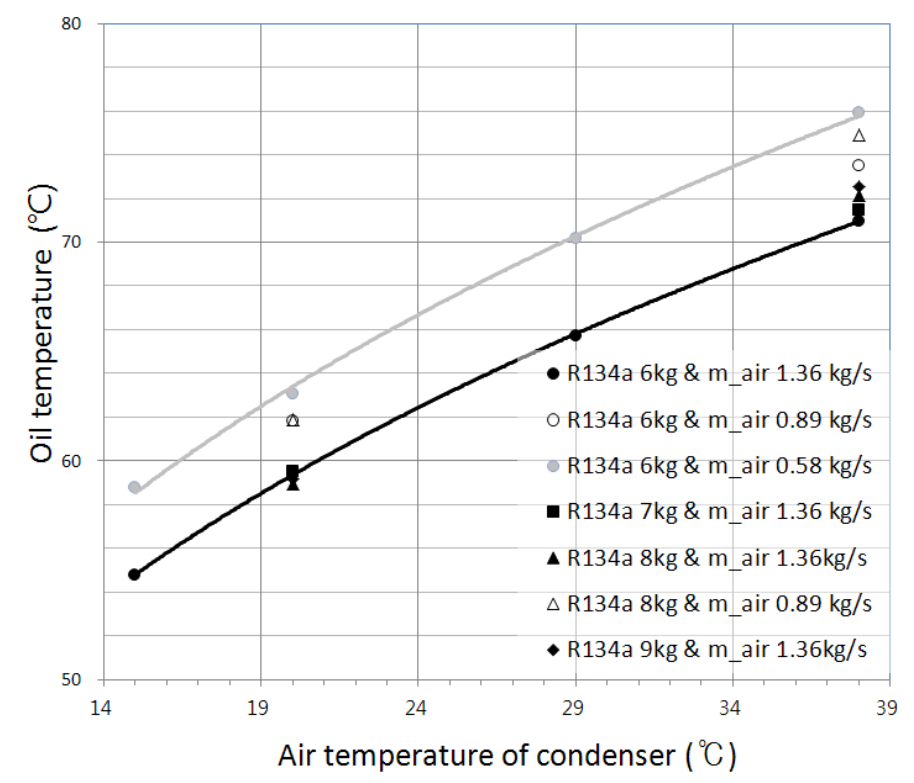

Figure 10. Comparison of Oil Temperature with Air Temperature of Condenser

\section{Conclusion}

Experiments of the loop type two-phase flexible thermosyphon heat exchanger for high speed rotating shaft heat release were conducted using R-134a as a working fluid. The results of experimental studies conducted on changes in working fluid refrigerant circulation rates, condenser air flow rates, and evaporator oil temperatures following changes in spaces between internal discontinuous pins of condenser with internal fins and external plate fins analyzed in comparison with simulation results are summarized as follows.

(1) Changes in the temperatures at the outlet of the condenser with internal fins and external plate fins were shown to be a little smaller. Therefore, it can be seen that as the spaces between internal discontinuous pins decreased, the heat transfer performance increased. 
(2) As the spaces between internal discontinuous pins of condenser with internal fins and external plate fins decreased, pressure drops increased.

(3) As the temperature of the air flowing in the condenser with internal fins and external plate fins increased, the condensation heat transfer rate of the thermosyphon heat exchanger increased.

(4) As the condenser refrigerant inflow temperature increased, the condensation heat transfer rate of the thermosyphon heat exchanger increased.

\section{References}

[1] S.H. Rhi, "Heat Transfer in the Presence of Steam Condensation in a Horizontal Tube", International Journal of Air-Conditioning and Refrigeration, vol.11, no.4, (2003), pp.159 169.

[2] E. P. Ananiev, L. D. Boyko, and G. M. Kruzhilin, "Heat Transfer in the Presence of Steam Condensation in a Horizontal Tube", Int. Heat Transfer Conf., Boulder, Colorado, Int. developments in heat transfer, Pt. II, Paper 34, pp. 290-295, W. V., Lehner, W. (eds.) Euro-Par 2006, LNCS, Springer Heidelberg vol. 4128, (2006), pp. 1148-1158.

[3] K.Y. Han, "Effect of Micro Grooves on the Performance of Condensing Heat Transfer of the Micro Grooved Thermosyphons", International Journal of Air-Conditioning and Refrigeration, Vol.10, No.4, (2002), pp.184 191.

[4] Chen, K.S. and Chang, Y.R., 1988, Steady-State Analysis of Two-Phase Natural Circulation Loop, Int. J. Heat Mass Transfer, vol.31, no.5, pp.931 940

[5] K. Han, D. H. Cho and T. W. Lim, "Characteristics of Boiling Heat Transfer of Themosyphon Heat Exchangers with Helical Grooves", (2005).

[6] K. Mou and H. Chang, "Study on Percentage of liquid Filling of separate type Heat Pipe", 3IHPS, (1988).

[7] B. Crain and K.J. Bell, "Forced Convection Heat Transfer to A Two Phase Mixture of Water and Steam in a Helical Coil", AIChE Sym. series, vol.69, no.131, (1973), pp.30 36.

[8] A. Faghri, M.M. Chen and M. Morgon, "Heat Transfer Characteristics in Two-Phase Closed Conventional and Concentric Annular Thermosyphons", ASME J. of Heat Transfer, vol.111, (1989), pp.611 618. 
International Journal of Control and Automation

Vol. 9 No. 5 (2016) 